\title{
Properties of the solutions of those equations for which the Krasnoselskii iteration converges
}

\section{IOAN A. RUS}

\section{ABSTRACT.}

Let $(X,+, \mathbb{R}, \rightarrow)$ be a vectorial $L$-space, $Y \subset X$ a nonempty convex subset of $X$ and $f: Y \rightarrow Y$ be an operator with $F_{f}:=\{x \in Y \mid f(x)=x\} \neq$ $\emptyset$. Let $0<\lambda<1$ and let $f_{\lambda}$ be the Krasnoselskii operator corresponding to $f$, i.e.,

$$
f_{\lambda}(x):=(1-\lambda) x+\lambda f(x), x \in Y .
$$

We suppose that $f_{\lambda}$ is a weakly Picard operator (see I. A. Rus, Picard operators and applications, Sc. Math. Japonicae, 58 (2003), No. 1, 191-219).

The aim of this paper is to study some properties of the fixed points of the operator $f$ : Gronwall lemmas and comparison lemmas (when $(X,+, \mathbb{R}, \rightarrow, \leq)$ is an ordered $L$-space) and data dependence (when $X$ is a Banach space). Some applications are also given.

Department of Mathematics

BABEŞ-BOLYAI UNIVERSITY

KOGĂLNICEANU 1, 400084, CLUJ-NAPOCA, ROMANIA

E-mail address: iarus@math.ubbcluj.ro 